\title{
Evaluation of Caspase 9 Activity Level in Hela Cell Line Exposed to Cytotoxic Dose of Aspirin
}

\begin{abstract}
Naji T, Khajavi AF, Mir M*
Tahereh Naji, Department of Basic Sciences, Faculty of Pharmacy, Pharmaceutical Sciences Branch, Islamic Azad University, Tehran - Iran (IAUPS ) (e-mail: tnaji2002@gmail.com)

Amirfarzad Khajavi, Department of Basic Sciences, Faculty of Pharmacy, Pharmaceutical Sciences Branch, Islamic Azad University, Tehran - Iran (IAUPS ) (e-mail: Frzd.khjvi@yahoo.com)

Seyedeh Mahsa Mir *(corresponding author), Department of Cellular and Molecular Biology, Faculty of Biology, Pharmaceutical Sciences Branch, Islamic Azad University, Tehran, Iran

(Email: mmahsamir@gmail.com)

Abstract: The research have shown that aspirin may have anticancer effects on several types of cancer cells. The aim of this study was to determine the effects of aspirin on apoptosis in cervical cancer (Hela) cells exposed to aspirin through evaluation of caspase-9 activity. In this experimental laboratory study, cervical cancer cells were purchased from Iran Cell Bank (Pasteur Institute, Tehran, IRAN). Cell lines were cultured in DMEM culture media. The cells were transferred to 6 well plate and incubated for 24 hours. After incubation, the cells were exposed to 10, 1, 0.1, 0.01, 0.001 and $0.0001 \mathrm{mg} / \mathrm{ml}$ of aspirin and cell viability was measured using MTT assay method. Caspase-9 activity in response to IC-50 dose of aspirin was evaluated using ELISA reader. The results indicated that the caspase-9 activity was significantly higher in cervical cancer cells exposed to IC50 dose of aspirin than control group $(P<0.05)$. Our findings demonstrated that IC50 dose of aspirin induces intrinsic apoptotic pathway in cervical cancer cells.
\end{abstract}

Keywords: Aspirin, HELA cells, Caspase-9.

\section{Introduction}

Caspase-9 is a key player in the intrinsic or mitochondrial pathway which is involved in various stimuli including chemotherapies, stress agents and radiation. Failing to activate caspase-9 has profound physiological and pathophysiological outcomes, leading to degenerative and developmental disorders even cancer[1].

HeLa cells were named for Henrietta Lacks, who died in 1952 from an infection of a special type of cancer[2]. As a nearly ubiquitous inhabitant of laboratories using tissue culture techniques, its aggressive growth characteristics make it a problematic contaminant that can overgrow less robust cell lines [3].

Aspirin is integral to the secondary prevention of cardiovascular disease and acts to impair the development of platelet-mediated atherothromboembolic events by irreversible inhibition of platelet cyclooxygenase-1 (COX1) [4].

Previous studies have shown that NSAIDs play significant role in apoptosis and caspase enzymes activation in cancer cells including cervical cancer cells [5], [6]. The aim of this study was to evaluate the effects of IC50 dose of aspirin on caspase 9 activity level in cervical cancer cells.

\section{Material and methods}

In this experimental laboratory study, cervical cancer cells were purchased from Iran Cell Bank (Pasteur Institute, Tehran, IRAN). Cell lines were cultured in DMEM culture media. The cells were transferred to 6 well plate and incubated for 24 hours. After incubation, the cells were exposed to 10, 1, 0.1, 0.01, 0.001 and 0.0001 
$\mathrm{mg} / \mathrm{ml}$ of aspirin and cell viability was measured using MTT assay method. Caspase-9 activity in response to IC50 dose of aspirin was evaluated using ELISA reader.

\section{Results}

The results indicated that the caspase- 9 activity was significantly higher in cervical cancer cells exposed to IC50 dose of aspirin than control group $(\mathrm{P}<0.05)$ (Figure I).

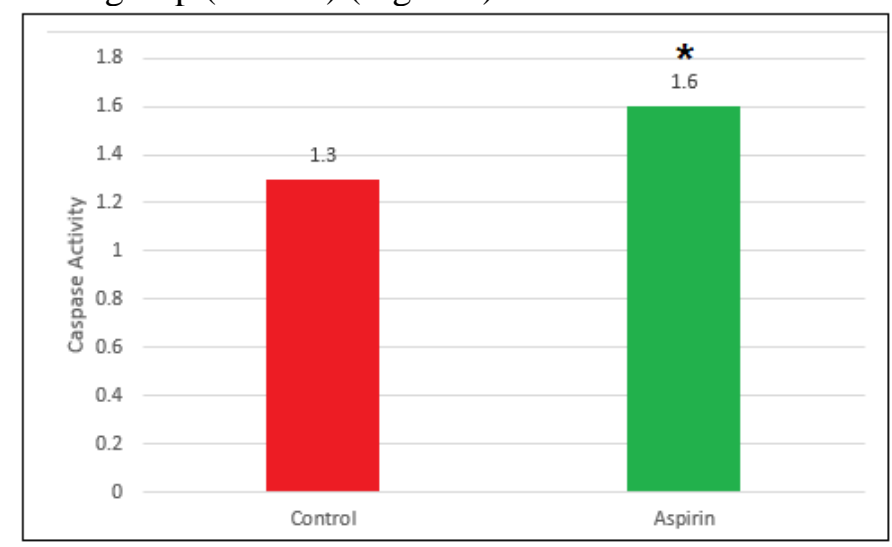

Fig. 1. Caspase 9 activity level in cervical cancer cells exposed to IC50 dose of aspirin compared with control group. * indicates significant difference at $\mathrm{p}<0.05$.

\section{Discussion}

Our findings indicated that aspirin induces apoptosis in cervical cancer cells through enhancing of caspase 9 activity level which is involved in intrinsic apoptosis pathway. In line with our finding recent data have suggested that regular aspirin use improves overall and cancer-specific survival in the subset of colorectal cancer (CRC) patients [7]. Aspirin is also a promising chemopreventive agent and exerts significant therapeutic potentials in pancreatic cancer [8]. NSAIDs and aspirin after but not before diagnosis were associated with improved breast cancer survival, including breast-cancer-specific mortality [9]. The research also have shown that aspirin may reduce the risk of endometrial cancer [10]. The change of caspase-9 expression in some cancer cells suggests that it may be involved in the carcinogenesis cancer cells. The overexpression of caspase-9 exhibits an inhibitory role in cancer growth and proliferation while promoting apoptosis [11]. It has been shown that aspirin can induce the antitumor effect mediated by caspase pathway in cervical cancer cells [12]. In a study it has been demonstrated that aspirin treatment caused changes in the mitochondrial membrane potential, release of cytochrome c from mitochondria, and activation of caspase-9 and -3 [13]. Caspase enzymes are also involved in aspirin-induced apoptosis in gastric cancer cells [14].

\section{Conclusion}

Our findings demonstrated that IC50 dose of aspirin induces intrinsic apoptotic pathway in cervical cancer cells.

\section{Acknowledgment}

We appreciate all who helped us to exert this study

\section{References}

[1] Li P, Zhou L, Zhao T, Liu X, Zhang P, Liu Y, Zheng X, Li Q. Caspase-9: structure, mechanisms and clinical application. Oncotarget. 2017;8(14):23996-24008

[2] Verma RP, Hansch C.Chemical Toxicity on HeLa Cells. Curr Med Chem. 2006;13(4):423-48.

[3] Rahbari R, Sheahan T, Modes V, Collier P, Macfarlane C, Badge RM.A novel L1 retrotransposon marker for HeLa cell line identification. Biotechniques. 2009;46(4):277-84

[4] You BR, Park WH.Zebularine inhibits the growth of HeLa cervical cancer cells via cell cycle arrest and caspasedependent apoptosis. Mol Biol Rep. 2012;39(10):9723-31. 
[5] Chen RH, Tian YJ.Enhanced anti-tumor efficacy of aspirin combined with triptolide in cervical cancer cells. Asian Pac J Cancer Prev. 2013;14(5):3041-4.

[6] Cook NR, Lee IM, Zhang SM, Moorthy MV, Buring JE.Alternate-day, low-dose aspirin and cancer risk: long-term observational follow-up of a randomized trialAnn Intern Med. 2013;159(2):77-85..

[7] Kothari N, Kim R, Jorissen RN, Desai J, Tie J, Wong HL, et al.Impact of regular aspirin use on overall and cancerspecific survival in patients with colorectal cancer harboring a PIK3CA mutation. Acta Oncol. 2015;54(4):487-92.

[8] Jiang MJ, Dai JJ, Gu DN, Huang Q, Tian L.Aspirin in pancreatic cancer: chemopreventive effects and therapeutic potentials. Biochim Biophys Acta. 2016;1866(2):163-176

[9] Huang XZ, Gao P, Sun JX, Song YX, Tsai CC, Liu J, et al.Aspirin and nonsteroidal anti-inflammatory drugs after but not before diagnosis are associated with improved breast cancer survival: a meta-analysis. Cancer Causes Control. 2015;26(4):589-600.

[10] Neill AS, Nagle CM, Protani MM, Obermair A, Spurdle AB, Webb PM; et al.Aspirin, nonsteroidal antiinflammatory drugs, paracetamol and risk of endometrial cancer: a case-control study, systematic review and metaanalysis. Int J Cancer. 2013;132(5):1146-55.

[11] Xu D, Wang C, Shen X, Yu Y, Rui Y, Zhang D, Zhou Z.Apoptotic block in colon cancer cells may be rectified by lentivirus mediated overexpression of caspase-9. Acta Gastroenterol Belg. 2013;76(4):372-80.

[12] Kim KY, Seol JY, Jeon GA, Nam MJ.The combined treatment of aspirin and radiation induces apoptosis by the regulation of bcl-2 and caspase-3 in human cervical cancer cell. Cancer Lett. 2003;189(2):157-66.

[13] Dikshit P, Chatterjee M, Goswami A, Mishra A, Jana NR.Aspirin induces apoptosis through the inhibition of proteasome function. J Biol Chem. 2006 ;281(39):29228-35.

[14] Gu Q, Wang JD, Xia HH, Lin MC, He H, Zou B, et al.Activation of the caspase-8/Bid and Bax pathways in aspirininduced apoptosis in gastric cancer. Carcinogenesis. 2005;26(3):541-6. 